\title{
DESPIDO POR CAUSA ECONÓMICA PREVENTIVO Y TEOREMA DE BAYES
}

\author{
Ignasi Beltran de Heredia Ruiz \\ Profesor Agregado y TU Acreditado \\ Universitat Oberta de Catalunya (UOC)
}

\begin{abstract}
El propósito de este ensayo es sugerir la aplicación del teorema de Bayes al despido preventivo por razones económicas. Especialmente porque en un entorno incierto, como ha demostrado la pandemia, podría ser un complemento apropiado (y tal vez, el único) para verificar a través de las probabilidades la fiabilidad de la causa incierta alegada.

The purpose of this essay is to suggest the application of the Bayes theorem to preventive dismissal on economic grounds. Specially because in a uncertainty environment, such as pandemic has shown, might be an appropriate complement (and perhaps, the unique) to verify through probabilities the reliability of the uncertain cause alleged.
\end{abstract}

Title: preventive dismissal on economic grounds and Bayes theorem

Palabras clave: despido económico preventivo, teorema de Bayes Key Words: preventive dismissal on economic grounds, Bayes theorem

IUSLabor 1/2021, ISSN 1699-2938, p. 66-98

DOI. 10.31009/IUSLabor.2021.i01.03

Fecha envío: 25.01.2021 | Fecha aceptación: 01.02.2021 


\section{Sumario}

1. Despido económico preventivo e incertidumbre

2. El (limitado) conocimiento pasado y la imaginación (sesgada) del futuro

2.1. El placer de pensar en el futuro y el optimismo no realista de las proyecciones

2.2. Imaginar el futuro para evitar daños y riesgos

2.3. El combustible para la imaginación del futuro: los recuerdos (agujereados) del pasado

3. Los límites del conocimiento presente: conclusiones a partir de datos incompletos y la resistencia a cambiar de opinión

3.1. Conclusiones a partir de datos incompletos

3.2. La resistencia a cambiar de opinión: el sesgo de confirmación

4. El conocimiento del pasado y la falsa percepción de que podemos predecir el futuro: el sesgo de la retrospección

5. Calcular lo desconocido a partir de lo conocido: el teorema de Bayes

6. ¿Puede extenderse lógica bayesiana al despido económico preventivo?

7. Valoración final

8. Bibliografía 


\section{Despido económico preventivo e incertidumbre}

La particularidad del momento que nos ha tocado vivir es que, en la era de la información ${ }^{1}$, el acceso a más datos, paradójicamente, no nos está permitiendo acceder a un nivel superior de certeza. En efecto, uno de los riesgos más generalizados es que " $a$ medida que crece la cantidad de conocimiento existente en el mundo, se puede ensanchar la brecha entre lo que sabemos y lo que creemos saber". Especialmente, por la simple razón de que, "un incremento exponencial de la cantidad de información disponible se traduce en un incremento exponencial de las hipótesis a investigar".

La cuestión es que, en este marco de incertidumbre, los seres humanos tenemos serias dificultades para hacer pronósticos fiables sobre el futuro (incluso, las personas con la condición de "expertas"). Siguiendo con Nate SILVER², "nuestras aproximaciones y suposiciones sobre el mundo son mucho más rudimentarias de lo que creemos. Abominanos la incertidumbre, aunque forme parte inextricable del problema que intentamos resolver". De modo que, preferimos olvidar que "nuestros modelos son meras simplificaciones del mundo y, nos convencemos que si cometemos un error, será marginal". Cuando en realidad, en los sistemas complejos, "los errores no se miden en grados sino en magnitudes" ${ }^{3}$. En un alarde de imprudencia injustificable (y de un estado de confianza que roza lo infantil), damos por válidas predicciones aparentemente precisas, cuando en realidad no lo son (es como decir que "uno es un buen tirador porque sus disparos siempre dan en el mismo lugar, aunque esté lejos del objetivo") ${ }^{4}$.

\footnotetext{
${ }^{1}$ SILVER, Nate, La señal y el ruido, Barcelona, Atalaya, 2014, pp. 64 y 303.

${ }^{2}$ SILVER, Nate, La señal y el ruido, op. cit., pp. 32, 63 y 64.

${ }^{3}$ De hecho, Gerd GIGERENZER (Decisiones instintivas, Barcelona, Ariel, 2018, p. 45), a diferencia del planteamiento "clásico" de la ciencia económica, que sostiene que "más información es siempre mejor a menos que los costes de adquirir conocimientos nuevos superen las ganancias previstas", entiende que, "incluso cuando es libre, hay situaciones en que más información es perjudicial (...). Más información privilegiada puede ayudar a explicar a posteriori el funcionamiento de ayer del mercado, pero no a pronosticar el de mañana".

${ }^{4}$ En efecto, (TALEB, Nassim., El cisne negro, Barcelona, Paidós, 2011, pp. 208 y 209) "el incremento de nuestro conocimiento está, de hecho, amenazado por el mayor crecimiento de la confianza, que hace que nuestro crecimiento en el conocimiento sea al mismo tiempo un crecimiento en la confusión, la ignorancia y el engreimiento". Y, esto es especialmente grave, por ejemplo (TALEB, Nassim, Jugarse la piel, Barcelona, Paidós, 2019, pp. 47, 324 y 325), porque tendemos a no prestar atención al efecto profundamente desestabilizante que pueden tener acontecimientos estadísticamente poco relevantes (o altamente improbables) y que se conocen como "riesgos de cola". Especialmente, porque en estos casos, el riesgo es exponencial y sistémico y con capacidad de producir desviaciones extremas. Lo que es ilustrativo (TALEB, Nassim, El cisne negro, op. cit., p. 211) de nuestra "arrogancia epistémica" y que produce un doble efecto: "sobreestimamos lo que sabemos e infravaloramos la incertidumbre, comprimiendo así la variedad de posibles estados inciertos (es decir, reduciendo el espacio de lo desconocido)". De hecho, la ingente cantidad de datos que la era de la información nos provee, por el momento, tampoco ayuda a esclarecer estos fenómenos, pues, (SILVER, Nate, La señal y el ruido, op. cit., pp. 17 y 303) el hecho de que la misma
} 
El artículo 51.1 ET, al describir las posibles causas económicas que justifican un despido colectivo, habla (parcamente) de la existencia de una situación económica negativa, añadiendo que, por tal, puede entenderse (entre otras) una situación de pérdidas "previstas". Y, de ahí, la doctrina ${ }^{5}$ habla de "despido preventivo", pues, "ya no es necesaria una situación real y presente, tan solo se requiere que las pérdidas se prevean" 6 .

El artículo 4.3 RD 1483/2012, por su parte, al concretar esta causa resolutoria materializada en la "previsión de pérdidas", exige al empresario que (además de aportar la documentación a que se refiere el artículo 4.2) informe de "los criterios utilizados para su estimación". Y se añade la necesidad de "presentar un informe técnico sobre el volumen y el carácter permanente o transitorio de esa previsión de pérdidas basado en datos obtenidos a través de las cuentas anuales, de los datos del sector al que pertenece la empresa, de la evolución del mercado y de la posición de la empresa en el mismo o de cualesquiera otros que puedan acreditar esta previsión".

La doctrina iuslaboralista ${ }^{7}$ ha apuntado que "la finalidad del despido colectivo por dicha causa es la de evitar futuras situaciones negativas, mitigables con una organización más adecuada de los recursos humanos en la empresa"; y es especialmente explícito en el caso de que se aleguen "pérdidas previstas". Y, más específicamente, sobre los despidos preventivos (siguiendo con el planteamiento de referencia sobre esta cuestión propuesto por José Luís MONEREO PÉREZ ${ }^{8}$ ), debe establecerse una distinción entre, por un lado, "despidos preventivos puros", esto es, "vinculados exclusivamente a la predecibilidad de hechos y situaciones futuras negativas para la organización productiva sin ningún soporte actual o de presente", y, por otro lado, "las meras previsiones de situaciones de

esté por encima de nuestra capacidad de procesarla supone un grave peligro. Y esto es así porque estos contienen excesivo "ruido" $\mathrm{y}$, al no poder identificar las "señales", todavía no somos capaces de transformarla en conocimientos útiles (el número de relaciones relevantes en los datos son mucho más reducidas que la información disponible).

5 SOLER FERRER, Felipe, “La nueva regulación del despido por causas objetivas”, Diario La Ley, núm. 7548, 2011 (versión digital).

6 También se ha afirmado que (SÁEZ LARA, Carmen, Reestructuraciones Empresariales y Despidos Colectivos, Valencia, Tirant Lo Blanch, 2015, p. 56) "es un ejemplo de situación económica negativa actual que, aunque aún no conlleva pérdidas, las determinará en una proyección de la misma hacia el futuro, por lo que también debe ser sometido el control causal a las exigencias derivadas de los criterios interpretativos bien conocidos de la razonabilidad y la proporcionalidad".

${ }^{7}$ MONEREO PÉREZ, José Luís y GUINDO MORALES, Sara, "El despido colectivo fundado en causas económicas”, Derecho de las relaciones laborales, núm. 9, 2018 (versión digital).

${ }^{8}$ MONEREO PÉREZ, José Luís, El despido colectivo y sus elementos configuradores tras las recientes reformas, op. cit., p. 30.

${ }^{9} \mathrm{Y}$ que añade que se refiere a "previsiones del tipo de situaciones de hechos futuros en atención a variables del mercado y previsiones desligadas enteramente de una causalidad actual determinante" 
futuro sobre la base de causas actuales, de presente". En estos segundos, "el elemento preventivo se construye sobre la base de una causalidad actual adecuada que puede ser pronosticada sobre la base de datos y hechos actualmente existentes con una mirada evolutiva hacia el futuro". Y, también en estos mismos, siguiendo con el mismo autor, puede apreciarse "la existencia de pruebas de hechos, pues se vinculan a la "actualidad" de la crisis y sus efectos hacia un futuro razonablemente previsible" ${ }^{10}$.

Así pues, centrando la atención en el despido por causas económicas preventivo "actual con proyección de futuro" (pues, el "puro" debe ser descartado, al no poderse sustentar sobre la base de dato alguno), es claro que contiene una predicción. Lo que, en términos jurídicos, plantea la problemática relativa a la acreditación de un acontecimiento incierto $^{11}$. De hecho, como se expondrá en la parte final del estudio, son muy pocos los testimonios judiciales (al menos que se tenga constancia) que recogen la idea del despido preventivo.

Por consiguiente, esta dimensión jurídica (la necesidad de acreditar un escenario futuro justificativo de un despido) está intrínsecamente unida a la toma de decisiones en contextos de incertidumbre ( $\mathrm{y}$, en especial, a las limitaciones humanas para hacerlo de forma fiable). Y, por consiguiente, si se aspira a descifrar el supuesto de hecho de la norma, en este estudio debe prestarse especial atención a los importantes avances alcanzados por la psicología de la conducta en las últimas décadas al respecto.

De hecho, podría decirse que esta comunión (jurídica/psicológica) es, en este ámbito (entre muchos otros), absolutamente inescindible. Y la alarma sanitaria derivada del COVID-19 es, probablemente, una de las situaciones en las que se ha evidenciado con mayor claridad lo recién expuesto. Especialmente, porque ha amplificado exponencialmente la potencialidad de ambas dimensiones: la eventual necesidad de despidos preventivos, por un lado; y la dificultad de tomar decisiones en un escenario tan incierto, por otro.

\footnotetext{
${ }^{10}$ En la doctrina judicial recogiendo este criterio (sin perjuicio de lo que se expondrá posteriormente), STSJ Canarias Las Palmas 26 de febrero 2013 (rec. 18/2012)

${ }^{11}$ En todo caso, para complementar esta aseveración, es importante tener en cuenta que la incertidumbre se refiere (SUNSTEIN, Cass R., Riesgo y razón, Buenos Aires, Katz, 2006, pp. 86 y 87) a que los resultados pueden identificarse, pero no pueden adjudicarse probabilidades (a diferencia de una situación de riesgo, en la que los diversos resultados pueden identificarse y pueden adjudicarse probabilidades a cada uno de ellos). O, como apunta Nate SILVER (La señal y el ruido, op. cit., pp. 43 y 44) se refiere a situaciones cuyo riesgo no se puede calcular. Y esto lo distingue claramente el "riesgo", pues, "es algo a lo que se le puede poner un precio" y que, de hecho, "lubrica las ruedas de la economía de libre mercado" (en cambio, la incertidumbre "las atranca")
} 
En definitiva, la posibilidad de plantear un despido de forma preventiva evidencia la oportunidad de esta aproximación que se propone en este estudio. Especialmente, porque la pregunta clave está en determinar si es posible concretar una circunstancia que está sometida a un factor de incertidumbre de tal entidad. De modo que, si la justificación del despido está consustancialmente unida a una predicción, desde un punto de vista jurídico, ¿cómo podemos saber de forma válida la certeza de la misma? O, dicho de otro modo, ¿en qué medida puede quedar acreditada la suficiencia de la causa para justificar los despidos proyectados?

La doctrina laboralista ha apuntado el carácter "arduo"12 de esta prueba o, incluso, su "imposibilidad"13. En este sentido se ha afirmado ${ }^{14}$ que "las conjeturas, los vaticinios y las especulaciones acerca de la evolución futura de la empresa se incorporan así como un elemento decisivo para justificar legalmente los despidos". O, como apunta VALDÉS DAL-RÉ15, “ ¿cómo puede lograrse que unas señales o indicios puedan proporcionar datos sobre una situación económica negativa, siendo así que ésta se configura legalmente como el efecto o la consecuencia, no de una conjetura, sino de un hecho?". Por su parte, José Luís MONEREO PÉREZ ${ }^{16}$ apunta que el peligro es que este marco normativo permita tener en cuenta "simples 'pronósticos'o indicios débiles de que podría pasar en el futuro. Al efecto, convendría recordar que ni siquiera la llamada 'ciencia económica' (que, en realidad, no son sino una ciencia social más) se ha mostrado capaz de realizar".

Sin embargo, estas afirmaciones podrían no casar con el hecho de que vivimos en un mundo rodeado de predicciones a futuro y son muchos los negocios jurídicos vinculados a escenarios inciertos. ¿Debemos colegir, entonces, que el ámbito del despido, en general, y del económico preventivo, en particular, es totalmente refractario a toda predicción acreditable y evaluable?

A mi entender (y esta es la hipótesis de este trabajo), si bien es cierto que debemos desconfiar de "ciertas" predicciones de los seres humanos (y así trataré de justificar por qué - alineándome con la "intuición" de los autores citados), en este ensayo se defiende

\footnotetext{
${ }^{12}$ FALGUERA i BARÓ, Miquel, "La causalidad de los despidos económicos, técnicos, organizativos y productivos después de la ley $3 / 2012$ ", op. cit., versión digital.

13 Antes de la reforma de 2012, MOLINS GARCÍA-ATANCE, "Las causas económicas, técnicas, organizativas y de producción del despido objetivo y colectivo", op. cit., versión digital.

${ }^{14}$ SOLER FERRER, Felipe, "La nueva regulación del despido por causas objetivas", op. cit., versión digital.

${ }^{15}$ Citado por FALGUERA i BARÓ, Miquel, "La causalidad de los despidos económicos, técnicos, organizativos y productivos después de la ley 3/2012”, op. cit., versión digital.

${ }^{16}$ MONEREO PÉREZ, José Luís, El despido colectivo y sus elementos configuradores tras las recientes reformas, op. cit., p. 30.
} 
que es posible hacer estimaciones fiables sobre escenarios inciertos a través de juicios de probabilidad. Incluso en el despido preventivo.

Y lo que se conoce como el Teorema de Bayes, y la sencilla fórmula matemática que lo sustenta, es la herramienta más adecuada para abordar estas situaciones. Erigiéndose, en hipótesis, en un posible instrumento aplicable al ámbito objeto de este análisis (entre otros muchos). De hecho, ante la posibilidad habilitada por la propia norma, puede decirse que es el "único" método de carácter "objetivo" que permitiría no sólo hacer estimaciones fiables, sino (y, muy especialmente) someterlas a su escrutinio por parte de todos los agentes implicados. De otro modo, la norma se proyectaría a un estadio de imposibilidad material de cumplimiento.

El objeto de este ensayo, pues, radica en abordar la posible aplicación de la lógica bayesiana a este específico (e importante) aspecto del Derecho del Trabajo.

No obstante, a los efectos que evidenciar la oportunidad y la necesidad de esta aproximación es esencial conocer, con carácter previo, los motivos por los que los "humanos" tenemos una capacidad de predicción tan limitada. Aunque este enfoque exigirá "apartarse" de la dogmática jurídica, entiendo que (como se ha avanzado), si se aspira a conocer la eficacia del sistema normativo (en la línea del realismo jurídico), es esencial comprender el razonamiento introspectivo de sus destinatarios (incluso, por debajo del nivel consciente). De otro modo, seguiremos proyectando marcos regulatorios a ciegas, desconociendo las "palancas" que promueven la acción o la omisión de las conductas individuales socialmente esperadas.

Con este propósito, y siempre pensando en las posibilidades de acreditar un despido preventivo, en la primera parte del ensayo, y a partir de las investigaciones de la psicología cognitiva en el ámbito del razonamiento y de la decisión, se tratará de evidenciar lo siguiente: primero, que no podemos fiarnos del conocimiento extraído de nuestra experiencia previa; segundo, que nuestro conocimiento del presente es profundamente limitado; y, tercero, que nuestras proyecciones a futuro están muy sesgadas. Este conocimiento evidenciará la oportunidad de apostar por el Teorema de Bayes como "único" medio para dar cumplimiento al mandato legal del subtipo recogido en el artículo 51.1 ET.

Con este objetivo, a efectos expositivos, se distinguirá (apartados 2 y 3 , respectivamente) entre el conocimiento que extraemos del pasado y cómo influye en nuestra imaginación del futuro, por un lado, del conocimiento limitado del presente, por otro. Y, posteriormente (apartado 4), volviendo a incidir sobre el conocimiento del pasado, se 
analizará su capacidad para inducirnos a pensar erróneamente que podemos predecir el futuro de forma "ajustada".

La buena noticia es que la lógica "bayesiana" podría contribuir a mitigar todas estas limitaciones (apartado 5). Y, por ello, podemos confiar en que sea un buen instrumento para acreditar los despidos por causas económicas preventivos (apartado 6).

\section{El (limitado) conocimiento pasado y la imaginación (sesgada) del futuro}

Desde el punto de vista fisiológico ${ }^{17}$, diversas evidencias muestran que el lóbulo frontal es la maquinaria cerebral fundamental que permite a los seres humanos proyectarse a sí mismos en el futuro. Sin el lóbulo frontal (como le sucedió al famoso caso de Phineas Cage $^{18}$, así como a otras personas a las que se han visto afectadas por patologías, accidentes o cirugías con el mismo efecto), estaríamos atrapados en el espacio y el tiempo inmediatos, anclados a "estímulos del presente”. Esta reclusión nos impediría imaginar el mañana y, por ello, permaneceríamos despreocupados por lo que nos pudiera deparar el más allá de este instante. Aunque seríamos capaces de comprender los conceptos de "tiempo" y "futuro", viviríamos en un mundo sin "más tarde" o en un "presente permanente". Esto es, en una especie de cadena perpetua en la cárcel del momento.

Así pues, (siguiendo con Daniel GILBERT"19), el lóbulo frontal "capacita a los adultos humanos sanos para pensar en la existencia a largo plazo", es una especie de "máquina del tiempo que nos permite abandonar el presente y experimentar el futuro antes de que ocurra" $^{20}$. Y lo hacemos instintivamente (impedirlo nos exige un esfuerzo). Pudiendo

\footnotetext{
${ }^{17}$ GILBERT, Daniel, Tropezar con la felicidad, Barcelona, Ariel, 2017, pp. 34 a 36.

${ }^{18}$ De hecho (siguiendo con GILBERT, Daniel, Tropezar con la felicidad, op. cit., pp. 30 a 34), en este famoso accidente ferroviario de mediados del Siglo XIX, la lesión sufrida en el lóbulo frontal tras el accidente con la barra de acero (atravesándole el cráneo, sin provocarle la muerte), afectó también a la capacidad de planificar y, por consiguiente, hacer proyecciones a futuro de él mismo (anclándolo en una vivencia de un 'presente permanente' - y, por tanto, despojándole de una de las facultades propiamente 'humanas'). Extensamente al respecto también DAMASIO (El error de Descartes, Santiago de Chile, Editorial Andrés Bello, 1996, pp. 23 y ss.).

${ }^{19}$ GILBERT, Daniel, Tropezar con la felicidad, op. cit., pp. 30 a 34.

${ }^{20}$ De hecho, una de las cualidades que más nos distingue del resto de seres vivos es nuestra capacidad de imaginar "objetos y acontecimientos que no existen en el reino de la realidad, y esta habilidad es la que nos permite pensar en el futuro. Como dijo un filósofo, el cerebro humano es una 'máquina de anticipación' y 'crear futuro' es lo más importante que hace". Sin embargo, conviene precisar que, aunque otras especies animales también tienen capacidad para crear futuro, sólo los humanos podemos hacer predicciones a largo plazo (y no sólo inmediatas, locales y personales). Tenemos capacidad de prever con la imaginación una serie de hechos que todavía no se han producido. Como apunta Yuval N. HARARI (Homo deus, Barcelona, Penguin Random House, 2016), "no hay otro animal que pueda medirse con nosotros, no porque carezcan de alma o de mente, sino porque carecen de la imaginación necesaria". De hecho, esta capacidad de
} 
pensar en el pasado o el presente, de forma predominante, nos proyectamos (invirtiendo materialmente mucho más tiempo en ello). Los motivos que nos llevan a actuar así pueden ser dos: primero, porque nos provee placer; y, segundo, porque nos permite protegernos a través de la prevención. Y, respecto de esto último, es importante tener en cuenta que las experiencias y conocimientos del pasado se erigen en la fuente principal para la planificación de medidas precautorias.

Permítanme que, en las páginas que siguen, me detenga brevemente en cada una de estas tres cuestiones (especialmente porque condiciona las proyecciones de viabilidad empresarial de forma determinante; y, por ende, puede afectar a la acreditación de los despidos preventivos).

\subsection{El placer de pensar en el futuro y el optimismo no realista de las proyecciones.}

Pensar en el futuro ${ }^{21}$ puede ser placentero (nos encanta soñar despiertos, porque es una fuente de placer); e, incluso, puede ser más placentero que experimentarlo. $\mathrm{Y}$, curiosamente, eso también nos lleva a sobreestimar la probabilidad de que ocurra en la realidad. Así, nos encanta predecir $\operatorname{cosas}^{22}$, pero (como se ha avanzado al inicio de este ensayo) no se nos da demasiado bien. De modo que tenemos un problema de predicción (y nos cuesta admitirlo). Somos, pues, proclives a sufrir lo que Daniel KAHNEMAN describe como un "optimismo no realista" (sesgo optimista). Y esta "peculiaridad" tiene unos efectos verdaderamente profundos en nuestro comportamiento, en general, y en el empresarial, en particular:

- En primer lugar, implica que sobreestimamos la probabilidad de que un acontecimiento pueda acontecer. En la medida que nuestro pensamiento estadístico es especialmente limitado ${ }^{23}$, tendemos a confundir lo poco conocido con lo improbable.

- En segundo lugar, y derivado de lo anterior, incurrimos de forma recurrente en la falacia de la planificación, construyendo escenarios de éxito, malinterpretando (y subestimando) los riesgos; y, por consiguiente, "sin reparar el alto potencial de errores y cálculos equivocados" 24 .

\footnotetext{
anticipar el futuro también posibilita una cualidad muy específica del homo sapiens contemporáneo: nos convierte en seres intencionales. Véase al respecto, TOMASELLO (Los orígenes culturales de la cognición humana, Buenos Aires, Amorrurtu Editores, 2007, pp. 34, 35, 39 y 40); y Gerd GIGERENZER, Decisiones instintivas, op. cit., p. 54.

${ }^{21}$ GILBERT, Daniel, Tropezar con la felicidad, op. cit., p. 37.

${ }^{22}$ SILVER, Nate, La señal y el ruido, op. cit., pp. 25.

${ }^{23}$ SILVER, Nate, La señal y el ruido, op. cit., pp. 507.

${ }^{24}$ KAHNEMAN, Daniel, Pensar rápido, pensar despacio, Barcelona, Debolsillo, 2012, p. 331.
} 
Ambos elementos, "describen una desconcertante limitación de nuestra mente: nuestra excesiva confianza en lo que creemos saber y nuestra aparente incapacidad para reconocer las dimensiones de nuestra ignorancia y la incertidumbre del mundo en que vivimos. Somos propensos a sobrestimar lo que entendemos del mundo y a subestimar el papel del azar en los acontecimientos" 25 .

En definitiva, no somos conscientes de nuestra ignorancia. O, dicho de otro modo, no somos conscientes de la existencia de lo que se conoce como "desconocidos desconocidos". Aspecto, cuyas profundas implicaciones, abordaré posteriormente.

\subsection{Imaginar el futuro para evitar daños y riesgos}

Pensar en el futuro también nos permite adoptar medidas preventivas para evitar el dolor y/o los daños ${ }^{26}$. Al simular el futuro, el cerebro trata de controlar las experiencias que va a tener y con esta anticipación tratamos de "controlar" el futuro, identificando y proyectando las posibles alternativas y escogiendo los mejores destinos y evitando los peores. Por consiguiente, tenemos una tendencia innata por el control (lo que, probablemente, ha sido uno de los factores determinantes de nuestra continuidad como especie). Y, de nuevo, el sesgo optimista (o el hecho de que "no sabemos que no sabemos") vuelve a tener un papel destacado en estas circunstancias, pues, tenemos una sensación de controlar los acontecimientos del futuro absolutamente infundada. O, como apunta Daniel GILBERT ${ }^{27}$, "el futuro es esencialmente distinto a lo que parece a través de nuestro 'previsionómetro". De modo que nuestra sensación de tripular nuestro destino es absolutamente fútil. $\mathrm{Y}$ esto es así porque nuestra imaginación tiende a nutrirse de nuestro conocimiento "disponible” (¿quién no tuvo que modificar sus previsiones anuales en marzo 2020?).

En efecto, proyectamos alternativas a partir de lo que nuestra mente es capaz de imaginar y nuestras experiencias pasadas son una de sus fuentes principales. En definitiva, el pasado es el principal combustible para poder imaginar escenarios de futuro. Aspecto que se abordará a continuación.

\footnotetext{
${ }^{25}$ KAHNEMAN, Daniel, Pensar rápido, pensar despacio, op. cit., p. 27.

${ }^{26}$ GILBERT, Daniel, Tropezar con la felicidad, op. cit., pp. 40 a 43.

${ }^{27}$ GILBERT, Daniel, Tropezar con la felicidad, op. cit., p. 43.
} 
2.3. El combustible para la imaginación del futuro: los recuerdos (agujereados) del pasado

Nuestra visualización del pasado (los recuerdos) está plagada de agujeros (es obvio que no podemos recordarlo todo con minucioso detalle); y, por ello, nuestra memoria sufre defectos importantes.

A partir de esta realidad, el problema se produce a la hora de rememorar estos recuerdos. $\mathrm{Pues}^{28}$, la memoria es "constructiva", "toma fragmentos de lo que hemos vivido y el marco de la historia de lo sucedido". Aunque nuestros "sentidos, la atención y nuestra capacidad de interpretación no fueron capaces de captarlo todo hasta el más mínimo detalle (...), cuando evocamos el recuerdo, este parece estar intacto (...), creando un nuevo instante en nuestra memoria, como si llegara de una realidad paralela". Detrás de un recuerdo, exponen las citadas autoras, "hay trabajo y un esfuerzo artístico". Por consiguiente $^{29}$, la memoria crea a la vez que preserva. Tenemos una memoria "muy fragmentada y excéntrica y creativa". En efecto, inventa nuevas historias en todo momento y esta reconstrucción la ejecutamos inconscientemente (no a propósito): "inventamos, estructuramos, moldeamos y, de repente, hemos incluido cosas que no hemos vivido, sino leído, oído o visto".

Y, para complementar esta aproximación, es muy importante tener en cuenta que "cuando el cerebro rellena los agujeros de sus descripciones del ayer y del mañana, suele utilizar un material llamado 'hoy" 30. De modo que "las personas recuerdan de forma errónea su pasado, pues creen que una vez pensaron, hicieron y dijeron lo que piensan, hacen y dicen en la actualidad". Y es lógico que así sea, pues, dado que "las predicciones sobre el futuro se realizan en el presente, reciben la inevitable influencia de éste"31.

Este carácter reconstructivo y plástico de nuestros recuerdos tiene un importante efecto, pues, como se ha avanzado, nuestra proyección a futuro se nutre, en gran medida, de esta

\footnotetext{
${ }^{28}$ OSTBY, Hilde, y OSTBY, Ylva, El libro de la memoria, Barcelona, Ariel, 2019, p. 71.

${ }^{29}$ OSTBY, Hilde, y OSTBY, Ylva, El libro de la memoria, op. cit., pp. 69, 73, 104 a 106.

${ }^{30}$ GILBERT, Daniel, Tropezar con la felicidad, op. cit., p. 133 y 266.

${ }^{31} \mathrm{O}$, como expone el mismo autor citado, en otro pasaje muy ilustrativo (134 y 145), "el presente colorea con ligeras pinceladas el pasado que recordamos, pero se emplea a fondo a la hora de influir en el futuro imaginado. Dicho de forma más simple: muchos de nosotros lo pasamos mal al imaginar un mañana muy distinto al hoy, y nos resulta difícil imaginar que alguna vez pensaremos, querremos o sentiremos algo distinto a lo que pensamos, queremos o sentimos ahora". De modo que "estamos atrapados en un lugar, un tiempo y una circunstancia, y nuestros intentos de usar la mente para trascender esas fronteras son, la mayoría de las veces, infructuosos". Especialmente porque la "imaginación no puede trascender con facilidad las fronteras del presente".
} 
fuente de información ${ }^{32}$. Lo que pone en seria evidencia la certidumbre de nuestra capacidad de imaginación y, con ella, de predicción y de planificación (aspecto sobre el que se incidirá con más detalle en el apartado 4). Dicho de otro modo, el principal instrumento que empleamos para proyectar el futuro ${ }^{33}$, tiene una desviación de tal calibre que los desajustes que provoca son particularmente desconcertantes ${ }^{34}$. Y es fácil advertir su impacto en el mundo empresarial (tanto en las iniciativas exitosas como en las que finalizan con un fracaso).

Este problema se agrava porque (como se analizará a continuación) hay elementos para cuestionar nuestra capacidad para gestionar la información en el momento presente (mientras lo estamos experimentando).

\section{Los límites del conocimiento presente: conclusiones a partir de datos incompletos y la resistencia a cambiar de opinión}

En el epígrafe anterior se han descrito los factores que cuestionan nuestra capacidad predictiva, a partir del papel que juega la realidad del momento al rememorar el conocimiento pasado y la proyección de este último a la hora de imaginar el futuro. Este escenario (en términos de planificación) se agrava porque hay dos factores que interfieren en nuestra comprensión de la realidad que estamos experimentando en el momento:

\footnotetext{
${ }^{32}$ Aunque, siguiendo a Michael S. GAZZANIGA (El instinto de la conciencia, Barcelona, Paidós, 2019, p. 172), también tenemos capacidad de hacer planificaciones respecto de cosas que no hemos experimentado antes. De modo que planificamos utilizando modelos internos para simular el futuro, recordando acontecimientos pasados y recombinando los recuerdos de formas diversas a "fin de producir una serie de planes para adaptarnos a posibles circunstancias futuras (...). A medida que las experiencias y los recuerdos que estas producen se van acumulando, aumenta la información de la que dispone el protocolo de planificación, que podrá combinar una gama más amplia de escenarios futuros. Cuantas más experiencias hayamos tenido, más opciones podrá similar nuestro cerebro".

${ }^{33}$ GILBERT, Daniel, Tropezar con la felicidad, op. cit., p. 98.

${ }^{34}$ Como expone Daniel GILBERT (Tropezar con la felicidad, op. cit., p. 109), "el error que cometemos al no reconocer de forma momentánea el truco de rellenar los recuerdos y aceptar la validez de las evocaciones y la percepción es el mismo error que cometemos al imaginar el futuro". Especialmente porque (112 y 114) "al imaginar el futuro, solemos hacerlo con el punto ciego de la imaginación, y esa tendencia puede hacer que imaginemos de forma errónea acontecimientos futuros cuyas consecuencias emocionales intentamos procesar"; $\mathrm{y}$, a pesar de todas estas carencias, "no podemos evitar esperar que el futuro se desarrolle con los detalles que hemos imaginado". En la medida que la memoria "no es una secretaria sumisa que toma nota de todas nuestras experiencias, sino una sofisticada correctora que marca y archiva los elementos clave de una experiencia y luego utiliza esos elementos para reescribir la historia cada vez que la releemos", tiende a presentarnos de forma incorrecta el pasado, nos hace imaginar de forma errónea el futuro.
} 
- En primer lugar, porque 35 "no hay escapatoria al hecho de que los seres humanos somos criaturas pequeñas, dotadas sólo de unos pocos e inadecuados canales para recibir toda la compleja información que nos llega del exterior" ${ }^{\text {"3 }}$. Y tomamos decisiones en consecuencia; y,

- En segundo lugar, una vez nos hemos formado una opinión, somos muy poco proclives a aceptar un cambio de la misma.

A continuación, se exponen brevemente estas dos importantes ideas.

\subsection{Conclusiones a partir de datos incompletos}

Las personas tenemos serias dificultades para, como se ha avanzado, asumir que "no sabemos que no sabemos". Y es obvio que, ante "desconocidos desconocidos" (si no sé que no sé), estamos particularmente expuestos al error. Especialmente porque, siguiendo con Nate SILVER 37 “es una situación que ni siquiera nos hemos planteado, ya sea debido a una especie de bloqueo mental que nos impide imaginar esa situación o bien porque nuestra experiencia no basta para imaginarla; en cualquier caso es como no existiera"38. Eso implica que, al no ser capaces de realizar pronóstico alguno, quedamos absolutamente expuestos al azar.

Las implicaciones (personales y profesionales) de esta particularidad "tan humana" son de tal magnitud que acongoja que no le prestemos mayor atención. De hecho ${ }^{39}$, cuando la información es escasa, no tenemos problemas en complementar rápidamente la información que nos falta con datos que no tenemos e intuitivamente "saltamos"

\footnotetext{
${ }^{35}$ DEUTSCH, David, La estructura de la realidad, Barcelona, Anagrama, 1999, versión digital.

${ }^{36}$ Sin olvidar que la incidencia de las simulaciones de nuestro cerebro. Éstas (FELDMAN BARRET, Lisa, La vida secreta del cerebro, Barcelona, Paidós, 2018, p. 46) son “suposiciones (...) de lo que sucede en el mundo. En cada momento de vigilia nos enfrentamos a información ambigua y llena de ruido procedente de los ojos, los oídos, la nariz y otros órganos de los sentidos. El cerebro usa nuestras experiencias pasadas para construir una hipótesis - la simulación-y la compara con la cacofonía que llega a nuestros sentidos. De este modo, la simulación deja que nuestro cerebro imponga significado en el ruido, seleccionando lo que sea pertinente e ignorando el resto. El descubrimiento de la simulación a finales de los años noventa marcó el inicio de una nueva era en la psicología y en la neurociencia. Las pruebas científicas indican que, en gran medida, lo que vemos, oímos, tocamos, saboreamos y olemos son simulaciones del mundo, no reacciones ante él"'.

${ }^{37}$ SILVER, Nate, La señal y el ruido, op. cit., p. 508.

${ }^{38}$ Siguiendo con Nate, SILVER (citando a Donald Rumsfeld - La señal y el ruido, op. cit., pp. 506), “existen conocidos conocidos, cosas que sabemos. También sabemos que existen desconocidos conocidos, es decir, que sabemos que hay algunas cosas que no sabemos. Pero luego están los desconocidos desconocidos, las que cosas que no sabemos que no sabemos)".

${ }^{39}$ KAHNEMAN, Daniel, Pensar rápido, pensar despacio, op. cit., pp. 117 y 118
} 
directamente a la conclusión que nos parece más verosímil. Y lo hacemos sin prestar excesiva atención sobre su exactitud. En realidad, la coherencia de nuestra "historia resultante" es tan firme que mostramos una confianza ciega en su certeza ${ }^{40}$.

En todo caso, como apunta Kathryn SCHULZ41 "creer cosas basadas en pruebas deficientes es el mecanismo que hace funcionar la milagrosa maquinaria de la cognición humana". En efecto, nuestro razonamiento inductivo se fundamenta en esta estrategia, pues, no paramos de hacer conjeturas sobre la base de la experiencia pasada. Creemos que un hecho es más probable basándonos en nuestra propia experiencia anterior (olvidándonos si es lógicamente válido y teóricamente posible). Hacemos grandes conclusiones basándonos en datos muy pequeños ${ }^{42}$. De ahí que,

- Por un lado, seamos esencial e inevitablemente falibles, pues, aunque nuestras conclusiones pueden ser probabilísticamente ciertas, son posiblemente falsas; y,

- Por otro lado, "dado que el único propósito del razonamiento inductivo es extraer presuposiciones generales basadas en pruebas limitadas, es una máquina formidable para generar estereotipos" $" 3$.

\footnotetext{
${ }^{40}$ Para ilustrar, siguiendo con un ejemplo que expone Daniel KAHNEMAN, les ruego que reparen en la siguiente frase:

“ ¿Será Mindik una buena líder?

Ella es inteligente y fuerte...”.
}

Si tuvieran que responder a esta pregunta (pueden volverla a leer si quieren), lo más probable es que la mayor parte de ustedes responderían afirmativamente. Permítanme que (siguiendo con el citado autor) trate de explicarles cómo actuamos en estas situaciones: escogemos "la mejor respuesta basada en la muy limitada información disponible, pero adelantamos acontecimientos". Y lo hacemos (adelantar las conclusiones) porque no tenemos toda la información sobre Mindik. En efecto, “¿qué pasaría si los dos siguientes adjetivos fuesen corrupta y cruel?". Si tuviéramos esta información complementaria, probablemente, modificaríamos nuestra conclusión inicial. Sin embargo, sin saber estos datos, nos hemos lanzado a ciegas a considerar que Mindik sería una fantástica líder. Y, en paralelo, también les ruego que reparen qué es lo que no hacemos en estos casos: no nos preguntamos qué deberíamos saber antes de formarnos una opinión sobre la calidad de liderazgo de una persona. Y, por consiguiente, no evaluamos si la información inicialmente facilitada (inteligente y fuerte) es verdaderamente determinante para saber si Mindik podría ser una buena líder.

${ }^{41}$ SCHULZ, Kathryn, En defensa del error, Madrid, Siruela, 2015, pp. 113, 116, 119 y 121.

42 Al hilo de lo anterior, lo que se conoce como "efecto halo" es especialmente ilustrativo de nuestra tendencia "humana" a saltar a las conclusiones (aunque hay muchos otros). Así, por ejemplo, (SUTHERLAND, Stuart, Irracionalidad: el enemigo interior, Madrid, Alianza, 1996, p. 49) "si alguien posee un rasgo positivo destacado (disponible), es probable que los demás consideren el resto de sus rasgos mejor de los que en realidad son". Extremo especialmente explotado, entre otros ámbitos, en la publicidad en la que aparecen deportistas profesionales ("si juega bien a la pelota, también debe ser bueno seleccionando la mejor hamburguesa").

${ }^{43}$ Aunque, como expone Gerd GIGERENZER (Decisiones instintivas, op. cit., p. 23), no debería concluirse que nuestra inteligencia no pueda funcionar sin pensamiento consciente: "seria un error presuponer que la 
Reparen que, a pesar de estos "saltos", no tenemos problemas para aceptar estas conclusiones como verdaderas. Aunque se basen en datos manifiestamente parciales y/o incompletos. De modo que, no tenemos ningún inconveniente en actuar como si "lo que vemos es todo lo que hay" (y que Daniel KAHNEMAN lo sintetiza con esta frase: "what you see is all there is" - WYSIATI-abreviatura de las iniciales) ${ }^{44}$. De hecho, como expone Kathryn SCHULZ ${ }^{45}$, nos gusta explicar las cosas incluso cuando la verdadera explicación se nos escapa. Y esto provoca un efecto, cuanto menos curioso, pues, "tenemos la sensación de estar en lo cierto porque tenemos la sensación de estar en lo cierto: tomamos nuestra propia certidumbre como indicador de exactitud". Y, añade, "la sensación de saber algo es increíblemente convincente y desmesuradamente satisfactoria". Y es esta firme convicción en la certeza de lo que creemos lo que nos impide pensar que, quizás, podemos estar equivocados. O, dicho de otro modo, "nuestra capacidad de hacer caso omiso al hecho de no saber algo funciona de maravilla".

Así pues, tenemos una desmesurada confianza en nuestras creencias, a pesar de que las hayamos obtenido a partir de muy pocos datos. Y, derivado de esta circunstancia, puede extraerse una conclusión que es absolutamente trascendente: "a menudo dejamos de tener en cuenta la posibilidad de que falte la evidencia que podría ser crucial en nuestro juicio"46. En efecto, reparen que "no reunimos el máximo de pruebas posible con el fin de llegar a una conclusión; llegamos a la máxima conclusión posible basándonos en el mínimo de pruebas posible" ${ }^{\text {47 }}$.

En definitiva ${ }^{48}$, aprobamos muchas creencias intuitivas e impresiones y, además, tendemos a ser insensibles a la cualidad y cantidad de la información que obtenemos de las mismas. Tendemos a "saltar a las conclusiones", sin dedicar excesivo tiempo a

inteligencia es necesariamente consciente y reflexiva". Extremo que le lleva a la conclusión de que es posible confiar en nuestra intuición. Especialmente, según este autor (169), “cuando hemos de pensar cosas difíciles de predecir y hay poca información". Pues (58), aunque nuestras decisiones instintivas parezcan simplistas, "su inteligencia subyacente reside en seleccionar la regla general correcta para cada situación".

${ }^{44}$ Como apunta Daniel KAHNEMAN (Pensar rápido, pensar despacio, op. cit., pp. 263 y 264): “La limitada información de que disponemos no puede bastarnos, porque en ella no está todo. Construimos la mejor historia posible partiendo de la información disponible, y si la historia es buena, la creemos. Paradójicamente, es más fácil construir una historia coherente cuando nuestro conocimiento es escaso, cuando las piezas del rompecabezas no pasan de unas pocas. Nuestra consoladora convicción de que el mundo tiene sentido descansa sobre un fundamento seguro: nuestra capacidad casi ilimitada para ignorar nuestra ignorancia".

${ }^{45}$ SCHULZ, En defensa del error, op. cit., pp. 84, 77, 74 y 73.

${ }^{46}$ KAHNEMAN, Daniel, Pensar rápido, pensar despacio, op. cit., pp. 120.

${ }^{47}$ SCHULZ, En defensa del error, op. cit., p. 123.

${ }^{48}$ KAHNEMAN, Daniel, Pensar rápido, pensar despacio, op. cit., pp. 118 y 119. 
cuestionar la coherencia de las mismas. Y no sólo eso, pues, en este proceso suprimimos la duda y la ambigüedad.

\subsection{La resistencia a cambiar de opinión: el sesgo de confirmación}

El hecho de que construyamos pensamientos a partir de datos incompletos o parciales no nos impide "apropiarnos" de tales ideas como si fueran de nuestra "propiedad"49. Y una vez lo hacemos ${ }^{50}$, tendemos a buscar evidencias o información que las confirmen (sesgo de confirmación $)^{51}$. $\mathrm{O}$, dicho de otro modo ${ }^{52}$, tenemos muchas dificultades para "ajustar correctamente nuestras creencias cuando nos enfrentamos a una nueva explicación"

De tal modo que, incluso, tendemos a distorsionar las pruebas cuando no concuerdan con nuestras creencias $^{54}$. Su evaluación queda sustancialmente sesgada por ellas, pues, hacemos todo lo posible para ignorar aquéllas que las refutan y/o a negarnos a creerlas ${ }^{55}$. En definitiva, automanipulamos nuestras convicciones: intentamos reprimir/olvidar o reinterpretar las informaciones que nos son desfavorables ${ }^{56}$.

49 THALER, Richard H., Todo lo que he aprendido con la psicología económica, Barcelona, Deusto, 2016, p. 373.

${ }^{50}$ SUNSTEIN, Cass R., Leyes de miedo, Buenos Aires, Katz, 2009, p. 147.

51 O, como afirma Daniel KAHNEMAN (Pensar rápido, pensar despacio, op. cit., p. 112), “Contrariamente a las reglas de los filósofos de la ciencia, que aconsejan contrastar hipótesis intentando refutarlas, la gente (y los propios científicos con bastante frecuencia) busca datos que puedan ser compatibles con las creencias que actualmente tiene". De ahí que, añado, no sea infrecuente que las personas leamos, veamos o escuchemos medios de comunicación para que precisamente nos digan confirmen - lo que queremos oír.

52 TIROLE, Jean, La economía del bien común, Barcelona, Debolsillo, 2018, p. 141.

${ }^{53}$ Lo que resulta particularmente preocupante si se tiene en cuenta que nuestras preconcepciones controlan nuestras percepciones e interpretaciones (OVEJERO BERNAL, Anastasio, Psicología social, Madrid, Biblioteca Nueva, 2015, p. 64). Esto es, las primeras impresiones tienen un poderoso efecto perseverante y son muy resistentes al cambio.

${ }^{54}$ SUTHERLAND, Stuart, Irracionalidad: el enemigo interior, op. cit., pp. 183 y 196.

55 Al respecto, Francis BACON (citado por Stuart SUTHERLAND, Irracionalidad: el enemigo interior, op. cit., p. 196) escribió "la razón humana, cuando ha adoptado una opinión, hace que todo lo demás la apoye y concuerde con ella. Y aunque haya mayor número de ejemplos, y de mayor peso, en el lado opuesto, los desatiende y desdeña o, mediante una distinción, los aparta y rechaza, para que, por esta perniciosa predeterminación, la autoridad de su primera conclusión permanezca inviolada". De hecho (siguiendo con el mismo autor), confirmando esta apreciación, diversas experimentaciones han evidenciado que "cuando se presentan dos pruebas contradictorias igual de sólidas (o débiles) se emplean criterios totalmente distintos para evaluar la que concuerda con las propias actitudes y la que las contradice".

56 TIROLE, Jean, La economía del bien común, op. cit., 151. Ver también TALEB, Nassim (El cisne negro, op. cit., pp. 215, 42 y 106). 
El efecto de este sesgo en las decisiones que afectan a una planificación o proyección es indudable, pues, puede inducirnos a mantener un rumbo a pesar de que nuevas evidencias sugieran que no alcanzará el resultado inicialmente previsto.

\section{El conocimiento del pasado y la falsa percepción de que podemos predecir el futuro: el sesgo de la retrospección}

En los epígrafes anteriores se ha descrito la "materia prima" a partir de la cual imaginamos escenarios posibles a medio y largo plazo (recuerden, conocimiento sesgado del pasado, "reconstruido" con información del presente - y que, a su vez, también puede ser parcial).

La conformación de nuestro juicio sobre el futuro con estos mimbres también nos induce a una idea equívoca sobre nuestra capacidad para predecirlo. Y es obvio - como pueden imaginar -, que el ámbito del despido preventivo no queda al margen de su influencia.

Y, de nuevo, el efecto de la poderosa regla WYSIATI anteriormente descrita vuelve a hacer acto de presencia en este estadio. Es muy frecuente que, a "toro pasado", sepamos que las cosas iban a suceder (por ejemplo, la crisis financiera o el divorcio de unos amigos), pero quienes pensaban que sucederían estas cosas, no podían probarlo de forma concluyente, de modo que, en muchas ocasiones, se trata de acontecimientos que no son predecibles. Así, se alcanza una apreciación especialmente relevante: "Lo perverso del uso del verbo saber en este contexto no es que algunas personas creyeran en una presciencia que no poseen, sino que el lenguaje supone que el mundo es más cognoscible de lo que realmente es. Ello contribuye a perpetuar una perniciosa ilusión. El núcleo de la ilusión es que creemos entender el pasado, lo cual supone que también el futuro puede conocerse, pero la verdad es que entendemos el pasado menos de lo que creemos"

Y esta es la base de lo que se conoce como el sesgo de la retrospección. Esto es, tendemos a revisar la historia de nuestras creencias pasadas a la luz de acontecimientos reales (ya acaecidos), lo que genera una poderosa ilusión cognitiva, pues, creemos encontrar una relación de causalidad entre los hechos acaecidos ${ }^{58}$. Y la certeza ilusoria de las

\footnotetext{
${ }^{57}$ KAHNEMAN, Daniel, Pensar rápido, pensar despacio, op. cit., p. 264.

${ }^{58}$ Como apunta Gerd GIGERENZER (Decisiones instintivas, op. cit., p. 93), la percepción retrospectiva, pues, es fácil; en cambio, la previsión (a futuro) es extremadamente compleja: "a posteriori, no hay dudas; sabemos lo que ha sucedido, y, si somos imaginativos, siempre podemos elaborar una explicación. En la previsión, no obstante, hemos de hacer frente a la incertidumbre". Incluso, cuando se trata de los análisis de los expertos (por ejemplo, de bolsa), sus predicciones están sistemáticamente por debajo del nivel del azar. De hecho (169), nuestra dificultad para predecir el futuro podría estar fundamentada en el hecho de que tendemos a articular estrategias que, al estar alimentadas retrospectivamente, se tornan complejas por exceso de información. De modo que no podamos identificar la parte de la información verdaderamente relevante de cara al futuro.
} 
retrospecciones alimenta nuestro exceso de confianza ${ }^{59}$. ¡Lo que nos lleva a pensar que podemos predecir nuevos hechos futuros!

Así, por ejemplo, la identificación de las "cadenas causales" que "han provocado" un determinado resultado electoral por parte de los (expertos) tertulianos al día siguiente de la votación es un buen ejemplo. O, en relación a la crisis sanitaria derivada del COVID19, en estos momentos, las "señales" se ven claras (hace unos meses era, sin duda, más difícil, incluso para la propia OMS). Por poner un ejemplo (entre otros muchos), la reacción del Mobile World Congress en Barcelona en marzo de 2020 ahora se ve (muy) acertada: hubiera convertido a la ciudad en un "HUB" de propagación planetaria (entonces, si lo recuerdan, se criticó por excesivamente prudente y alarmista).

A la luz de lo expuesto, no debería extrañarnos que veamos el mundo más ordenado, predecible y coherente de lo que realmente es ${ }^{60}$. Y esto nos lleva a lo que se conoce como el "problema del pavo". En efecto, Nassim TALEB ${ }^{61}$, se pregunta: “ ¿cómo podemos conocer el futuro teniendo en cuenta nuestro conocimiento del pasado; o de forma más general, cómo podemos entender las propiedades de lo desconocido (infinito) basándonos en lo conocido (finito)?"

Y para ello, como una derivada de lo que el filósofo Bertrand RUSSELL denomina el problema de la inducción (o problema del conocimiento inductivo ${ }^{62}$ ), y adaptando su ejemplo (referido a un pollo), les ruego que se imaginen en la siguiente situación:

Ustedes son un pavo y sus cuidadores residentes en Estados Unidos les dan de comer cada día. A medida que pasan los días, y en base a su conocimiento pasado, su confianza en los humanos se incrementará progresivamente e, incluso, llegarán a creer que la regla general de la vida es que a uno lo alimenten ( y además bien!), mirando por sus intereses.

No obstante, el día antes del Día de Acción de Gracias (Thanksgiving Day), al pavo (ustedes) le ocurrirá algo inesperado y dejarán de "gluglutear"... (describiendo lo que Nassim TALEB denomina como un "Cisne Negro" para el pavo).

El problema del pavo se puede generalizar a múltiples situaciones (salud, amor, negocios, amistad, trabajo, etc.) y está muy vinculado a nuestras expectativas. Sin duda el problema

\footnotetext{
${ }^{59} \mathrm{Y}$, a su vez, lo que se conoce como el "sesgo del resultado" también nos influye, pues, nos lleva a pensar, por ejemplo, que ciertos éxitos empresariales son replicables (obviando la extraordinaria incidencia del ciego azar y la suerte en los mismos).

${ }^{60}$ KAHNEMAN, Daniel, Pensar rápido, pensar despacio, op. cit., p. 268.

${ }^{61}$ TALEB, Nassim, El cisne negro, op. cit., pp. 87 y ss.

${ }^{62}$ Extensamente al respecto, DEUTSCH, David, La estructura de la realidad, op. cit.
} 
de la inducción vuelve a describir (y con toda crudeza) el poder de la regla WYSIATI; o, dicho de otro modo, el hecho de que nuestro conocimiento se induzca a partir de datos pasados hace que seamos incapaces de predecir los grandes fenómenos disruptivos de nuestra vida (incluidas las fracturas "Históricas"). Sin embargo, como apunta Daniel KAHNEMAN"63, "nuestra tendencia a construir $-y$ creérnoslas- narraciones del pasado hace que nos resulte difícil aceptar los límites de nuestra capacidad predictiva (...). Y no puede sorprendernos la poderosa intuición de que, en una retrospección, lo que hoy confiere sentido era ayer predecible. La ilusión de que entendemos el pasado fomenta el exceso de confianza en nuestra capacidad para predecir el futuro" ${ }^{\text {"64 }}$.

Así pues, y a modo de conclusión de lo expuesto hasta este momento, podemos confirmar la hipótesis de partida descrita en este ensayo: los seres humanos contemporáneos tenemos graves problemas para hacer predicciones. Especialmente porque no podemos fiarnos completamente del conocimiento extraído de nuestra experiencia previa, nuestras proyecciones a futuro están profundamente sesgadas por lo pretérito y "reconstruidas" por un conocimiento del presente extremadamente limitado. $\mathrm{Y}$, aunque pueda ser descorazonador, debemos resignarnos y asumir que se trata de una "cualidad" que traemos "de serie".

En todo caso, y en "descargo" de la propia especie humana, es lógico que así sea, pues ${ }^{65}$, percibimos muchísima más información de la que podemos considerar de manera consciente, y nuestra manera de afrontar este problema consiste en descomponer la información en rutinas y patrones. Y, al hacerlo, simplificamos en exceso (sin saber hasta qué punto son aproximadas).

Teniendo en cuenta lo anterior (y volviendo al objeto de este estudio), como se ha avanzado como hipótesis de este trabajo, las condiciones para la aplicación del despido preventivo no son las "óptimas". Por consiguiente, en aras a poder delimitar el supuesto de hecho de la norma parece que el "único" medio para dar cumplimiento al mandato legal es acudir a un método decisorio que permita superar todas estas limitaciones "humanas".

El teorema de Bayes podría ser la respuesta.

\footnotetext{
${ }^{63}$ KAHNEMAN, Daniel, Pensar rápido, pensar despacio, op. cit., pp. 285 y 286.

${ }^{64} \mathrm{Y}$, de nuevo, también cuestiona las opiniones de los "expertos", especialmente, cuando se ponen a hacer predicciones a largo plazo: creando apreciaciones inadecuadas de la incertidumbre y, consiguientemente, favoreciendo el exceso de confianza; y, con él, precipitando cegueras colectivas sobre el riesgo. ${ }^{65}$ SILVER, Nate, La señal y el ruido, op. cit., pp. 542 y 543.
} 


\section{Calcular lo desconocido a partir de lo conocido: el teorema de Bayes}

El teorema de Bayes (ministro, canónigo y matemático inglés del Siglo XVIII) permite hacer pronósticos probables a partir de datos del presente. Es decir, permite "calcular exactamente, no hacer una estimación a ojo, hasta qué punto es probable que una teoría, o una hipótesis, sea verdadera, teniendo en cuenta todo lo que sabemos"66. O, en términos algo más precisos ${ }^{67}$, puede ser definido como "una consecuencia inmediata de la ley de multiplicación que sirve para conocer las probabilidades finales de un suceso a partir de las probabilidades iniciales, dada cierta información o informaciones adicionales obtenidas"68.

La complejidad y derivadas del citado teorema exceden, con mucho, la atención que puede dedicarse en un estudio de carácter jurídico. Por este motivo, permítanme que, aprovechando su extraordinario carácter didáctico, les sintetice la exposición de Nate SILVER $^{69}$, tratando de centrarme únicamente en aquellos aspectos que faciliten su comprensión. Este teorema permite conocer qué probabilidades existen de que "una teoría o una hipótesis sea cierta si se produce un acontecimiento determinado" (es lo que se conoce como una "probabilidad condicional" "70). Y, lo más relevante es que la misma puede ser aplicada a múltiples situaciones. Aquí un ejemplo:

Imagínense que, viviendo en pareja, al volver de un viaje, descubre una prenda de ropa interior "extraña" en su cajonera. El hecho de que haya hecho este hallazgo es la condición para que se pregunte la probabilidad de que su pareja sea infiel. El teorema puede proporcionar una respuesta a esta duda, siempre que conozca tres factores:

Primero: qué probabilidades hay de que la aparición de la prenda de ropa sea una condición de que, efectivamente, se esté produciendo una infidelidad (esto es, que la hipótesis sea cierta). En este caso, la probabilidad no tiene porqué ser del 100\%, pues, si bien es cierto que, si su pareja es infiel, es fácil imaginar cómo ha llegado esa prenda a la cajonera, también lo es que es probable que, aunque se produzca este engaño, también es

\footnotetext{
${ }^{66}$ PIATTELLI PALMARINI, Massimo, Los túneles de la mente, Barcelona, Crítica, 1995, p. 108.

${ }^{67}$ SÁNCHEZ-RUBIO, Ana, "Los peligros de la probabilidad y la estadística como herramientas para la valoración jurídico-probatoria”, Revista Brasileira de Direito Processual Penal, Vol. 4, núm. 1, pp. 183214, 2018, p. 199.

${ }^{68}$ O bien, siguiendo a Stuart SUTHERLAND (Irracionalidad: el enemigo interior, op. cit., p. 270), la "mecánica" del Teorema también puede exponerse como sigue: "cuando se recibe nueva información sobre la probabilidad de un hecho, hay que unir dicha probabilidad a la del hecho en ausencia de nueva información, probabilidad que se conoce como tasa base (o probabilidad a priori)".

${ }^{69}$ SILVER, Nate, La señal y el ruido, op. cit., pp. 295 a 301.

${ }^{70}$ Es decir (SILVER, Nate, La señal y el ruido, op. cit., pp. 295), "nos indica qué probabilidades existen de que una teoría o una hipótesis sea cierta si se produce un acontecimiento determinado".
} 
posible que crea que su pareja tendría más cuidado para esconder su comportamiento. Así pues, supongamos, teniendo en cuenta lo expuesto, que la aparición de esta prenda conlleva un $50 \%$ de probabilidad de que se está produciendo un engaño.

Segundo: qué probabilidades hay de que la aparición de la citada prenda sea una condición para rechazar que se está produciendo una infidelidad (por consiguiente, que la hipótesis sea falsa). En este sentido, las alternativas "posibles" podrían ser muchas (aunque, algunas resulten incómodas, inverosímiles o meras "excusas baratas"). Imaginen que la probabilidad fuera del $5 \%$.

Tercero: antes de que encontrara la citada prenda de ropa, ¿qué probabilidad le concedía a que su pareja incurriera en una infidelidad? Esta "probabilidad previa" (o subjetiva) resulta particularmente compleja de determinar, especialmente, si tiene que estimarse una vez se ha producido el hallazgo de la prenda de ropa (idealmente, tendrían que determinarse estas "previas" antes del examen de las evidencias). Imaginen que fuera del $4 \%{ }^{71}$.

De modo que, en la versión más simple posible del teorema, la situación podría sintetizarse como sigue:

\section{Probabilidad previa}

\begin{tabular}{|l|l|l|}
\hline $\begin{array}{l}\text { Estimación inicial de las probabilidades de que } \\
\text { su pareja es infiel }\end{array}$ & $\mathrm{x}$ & $4 \%$ \\
\hline
\end{tabular}

2. Sucede algo: encuentra una prenda extraña

\begin{tabular}{|l|l|l|}
\hline $\begin{array}{l}\text { Probabilidad de que la prenda aparezca como } \\
\text { condición de que se está produciendo un } \\
\text { engaño }\end{array}$ & y & $50 \%$ \\
\hline $\begin{array}{l}\text { Probabilidad de que la prenda aparezca como } \\
\text { condición de que no se está produciendo un } \\
\text { engaño }\end{array}$ & $\mathrm{z}$ & $5 \%$ \\
\hline
\end{tabular}

\section{Probabilidad posterior:}

\footnotetext{
${ }^{71}$ Los datos estadounidenses que cita Nate SILVER (La señal y el ruido, op. cit., pp. 296) del año 2008 así lo establecen.
} 


\begin{tabular}{|l|c|c|}
\hline $\begin{array}{l}\text { Estimación corregida sobre las probabilidades } \\
\text { de que se esté produciendo un engaño teniendo } \\
\text { en cuenta que se ha encontrado la prenda de }\end{array}$ & $\frac{x y}{x y+z(1-x)}$ & $29 \%$ \\
ropa extraña
\end{tabular}

A la luz de estos cálculos, la "probabilidad posterior" es bastante baja. Esto es, sólo del $29 \%$. Y es posible que entiendan que el resultado final sea contraintuitivo, teniendo en cuenta el hallazgo de la prenda de ropa (encontrarla era bastante "incriminatorio", ¿no creen?).

El motivo de este resultado viene determinado por el hecho de que se ha asignado una probabilidad (previa) muy baja a la posible existencia de una infidelidad con anterioridad al descubrimiento de la prenda de ropa. Se ha partido de la base de que su pareja era "inocente" y eso "pesa mucho en el resultado final". O, como apunta Nate SILVER ${ }^{72}$, si "nuestras previas son potentes, pueden ser sorprendentemente resistentes a la aparición de nuevas evidencias" (aunque no tiene que ser necesariamente así, si las nuevas pruebas son especialmente "potentes").

La virtud del teorema es que, si aparecieran nuevos datos, puede volverse a calcular a partir de su conocimiento. De hecho, puede hacerse de forma constante (300), esto es, "cada vez que se nos muestra una nueva evidencia".

De modo que, siguiendo con el mismo ejemplo, si se hallara una nueva evidencia (por ejemplo, una segunda prenda en la misma cajonera), la "probabilidad posterior" (esto es, el 29\%) pasaría a convertirse en la "previa". Y los cálculos serían los siguientes:

\section{Probabilidad previa}

\begin{tabular}{|l|l|l|}
\hline $\begin{array}{l}\text { Estimación inicial de las probabilidades de que } \\
\text { su pareja es infiel }\end{array}$ & $\mathrm{x}$ & $29 \%$ \\
\hline
\end{tabular}

\section{Sucede algo: encuentra una prenda extraña}

\begin{tabular}{|l|l|l|}
\hline $\begin{array}{l}\text { Probabilidad de que la prenda aparezca como } \\
\text { condición de que se está produciendo un engaño }\end{array}$ & $\mathrm{y}$ & $50 \%$ \\
\hline $\begin{array}{l}\text { Probabilidad de que la prenda aparezca como } \\
\text { condición de que no se está produciendo un } \\
\text { engaño }\end{array}$ & $\mathrm{z}$ & $5 \%$ \\
\hline
\end{tabular}

${ }^{72}$ SILVER, Nate, La señal y el ruido, op. cit., pp. 297 y 299. 


\section{Probabilidad posterior:}

\begin{tabular}{|l|c|l|}
\hline $\begin{array}{l}\text { Estimación corregida sobre las probabilidades } \\
\text { de que se esté produciendo un engaño teniendo } \\
\text { en cuenta que se ha encontrado la prenda de ropa } \\
\text { extraña }\end{array}$ & $\frac{x y}{x y+z(1-x)}$ & $80 \%$ \\
\hline
\end{tabular}

De modo que la aparición de una segunda prenda provoca que la "probabilidad posterior" se dispare hasta el $80 \%$, alterando significativamente la valoración respecto del primer cálculo (y reforzándose, sólo entonces, la intuición derivada del primer hallazgo).

Así pues, a modo de conclusión, (siguiendo a SÁNCHEZ-RUBIO ${ }^{73}$ ) la inferencia bayesiana permite demostrar matemáticamente "que con el cálculo de probabilidades es posible representar de modo numérico un conjunto racional de creencias, de manera que se establezca una relación entre probabilidad e información. Más aún, (...) proporciona una vía de actualización de las creencias cuando aparece nueva información, con la sencilla modificación del valor atribuido a la probabilidad a priori”.

En el epígrafe que sigue, se abordará, en términos teóricos, la posible aplicación de esta teoría al ámbito del despido económico preventivo.

\section{6. ¿Puede extenderse lógica bayesiana al despido económico preventivo?}

El despido económico basado en una previsión de pérdidas ${ }^{74}$, en tanto que "subtipo" resolutorio, exige que se pruebe que "el escenario futuro se adecua a una mínima racionalidad desde la perspectiva de la gestión de mano de obra y los recursos financieros, organizativos y de perspectiva de mercado del producto o el servicio". Además, también se entiende que "el empleador tendrá que justificar una cierta proximidad temporal al momento del despido en términos racionales".

En este contexto y partiendo de la base de las profundas limitaciones ("de serie") del ser humano para hacer predicciones (expuestas en los epígrafes anteriores), podría decirse que, el supuesto de hecho de la norma exigiría (si o si) el uso de un instrumento que sea el reflejo más próximo posible a la idea de "racionalidad". El teorema de Bayes podría

\footnotetext{
${ }^{73}$ SÁNCHEZ-RUBIO, Ana, "Los peligros de la probabilidad y la estadística como herramientas para la valoración jurídico-probatoria", op. cit., p 2

${ }^{74}$ FALGUERA i BARÓ, Miquel, "La causalidad de los despidos económicos, técnicos, organizativos y productivos después de la ley 3/2012”, op. cit., versión digital.
} 
ser la mejor herramienta a nuestro alcance (y, probablemente, la única que "objetivaría" de algún modo el uso de este supuesto resolutorio).

En la jurisprudencia son pocos los testimonios sobre la aplicación de esta causa resolutoria (al menos, siendo "apelado" de forma "autónoma"). Uno de los pocos ejemplos (al menos, que se tenga constancia), puede encontrarse en la STS 25 de febrero 2015 (rec. 74/2014). En este caso (relativo a una productora de contenidos audiovisuales que presta servicios para una televisión pública autonómica) se entiende que concurre una situación económica negativa si se está "ante la inminente modificación del acuerdo de su casi único cliente, que la situaban en un escenario de pérdidas previsibles y partiendo de una situación de disminución del nivel de ingresos".

En la doctrina judicial, en términos doctrinalmente similares a los expuestos al inicio de este estudio (distinguiendo entre el despido preventivo "puro" y el "actual con proyección de futuro"), la STSJ AndalucíalSevilla 23 de enero 2019 (rec. 885/2018) que afirma "aquí solo cabe enjuiciar los despidos 'con causa actual pero con proyecciones secuenciales de futuro' que serían los que obedecen a meras previsiones sustentadas en una causalidad actual adecuada que puede ser pronosticado sobre la base de datos y hechos actualmente existentes con una mirada evolutiva hacia el futuro; y que a diferencia de los despidos preventivos puros, en los despidos con causa actual pero con proyecciones secuenciales de futuro sí podría apreciarse la existencia de hechos vinculados a la 'actualidad' de la crisis y sus efectos hacia un futuro razonablemente previsible, factor determinante de lo que podría venir después. Pero, no nos cabe enjuiciar hechos posteriores a la fecha de 
cese que carecen de vinculación con hechos actuales" ${ }^{\text {,75 }}$. Exigiéndose en estos casos también la denominada "conexión de funcionalidad"76.

Es probable que las dificultades probatorias (más exigentes para estos casos) se hayan erigido en uno de los motivos que expliquen la escasa conflictividad derivada de este "subtipo" resolutorio ${ }^{77}$.

No obstante, esto no debería ser un obstáculo para tratar de aplicar a estos supuestos el teorema de Bayes descrito (de hecho, está siendo aplicado a múltiples y complejos fenómenos - desde ataques terroristas, predicción de enfermedades como el cáncer o, como en nuestro ejemplo, para tratar de dilucidar si nuestra pareja nos engaña). De hecho, la Sala de lo Penal del Tribunal Supremo ha apelado a él como un medio para certificar

75 En términos similares, STSJ CanariaslLas Palmas 26 de febrero 2013 (rec. 18/2012). Y, con una aproximación más general, la STSJ Cataluña (2) 9 de junio 2016 (rec. 2167/2016; rec. 2735/2016) establece que "Por causa económica hay que entender la que actúa sobre el resultado de la gestión empresarial en su conjunto, sobre la relación de ingresos y costes, de beneficios y pérdidas, es decir, sobre el equilibrio de la empresa, cuya determinación se vincula a los ingresos y los costes, teniendo en cuenta la cantidad producida, la vendida y los ingresos generados por la venta, en función del precio, que depende de la demanda del mercado y del nivel de oferta. Estos elementos repercuten en el nivel óptimo de utilización del factor trabajo, y se integran en las causas económicas, de forma que la procedencia de la regulación no precisa una situación económica crítica, ni siquiera la existencia de pérdidas reales, sino que basta la previsión de pérdidas. También es causa económica la disminución persistente del nivel de ingresos ordinarios o de ventas. La existencia de una situación económica negativa puede habilitar la adopción de medidas de despido, ya que carecería de sentido obligar a las empresas a permanecer en situaciones negativas en tanto no tuvieran pérdidas , que muy posiblemente llevarían consigo, en el mejor de los casos, una más profunda reestructuración de los elementos empresariales y, en otros muchos supuestos, su simple desaparición. De esta manera, la extinción de contratos puede deberse a una situación de pérdidas ya exteriorizada o simplemente prevista. El objeto del despido colectivo es evitar situaciones futuras negativas, paliables con una más adecuada organización de los recursos humanos en la empresa, en volumen o en estructura u organización, pudiendo ser causa de un despido preventivo los efectos empresariales del nuevo marco regulador de una actividad" (y que también se recoge, entre muchas otras, en las SSTSJ Cataluña 10 de diciembre 2019, rec. 5537/2019; 12 de mayo 2016, rec. 1773/2016; y Asturias 27 de febrero 2018, rec. 3109/2017).

76 SSTSJ AndalucíalSevilla 23 de enero 2019 (rec. 885/2018); y Cataluña 10 de diciembre 2019 (rec. 5537/2019).

${ }^{77}$ Especialmente porque, recogiendo el criterio de Miquel FALGUERA i BARÓ ("La causalidad de los despidos económicos, técnicos, organizativos y productivos después de la ley 3/2012: reflexiones tras un año de doctrina judicial por la vía del artículo 124 LRJS”, Revista Jurisdicción Social, núm. 133, 2013, versión digital), "la Ley no regula el período de referencia y el ámbito de aplicación”. 
(o no) la ocurrencia de un hecho incierto ${ }^{78}$. En la jurisdicción contencioso-administrativa también pueden hallarse algún testimonio ${ }^{79}$.

El carácter objetivo de su formulación y la posibilidad de ir acumulando evidencias (permitiendo una revisión $-\mathrm{y}$ mejora- continua de las estimaciones iniciales) son probablemente los principales activos de esta metodología. Y, probablemente también, este análisis podría formar parte de la documentación que el empresario pusiera a disposición de los trabajadores durante el período de consultas y/o en la carta de despido.

De hecho, reparen que esta aproximación no es incompatible con la necesidad de que la causa alegada, en tanto que "no es expresiva de una situación real sino de una hipotética o presumible situación futura", sea "examinada y valorada con cautela"; y, por tanto, exigiéndose "una perfecta acreditación de hechos indiciarios de los que se pueda inferir racionalmente y con clara probabilidad, la existencia de pérdidas en el futuro que obligan a extinguir en el presente el contrato de trabajo" $"$.

De hecho, partiendo de las limitaciones "humanas" para hacer predicciones fiables, la evaluación de la situación de la empresa a partir de sucesivas aproximaciones a medida que se va obteniendo más información podría contribuir a disipar las dudas respecto a la acreditación de este subtipo resolutorio. Especialmente ${ }^{81}$, si la creencia previa (la probabilidad previa) se articulara a partir del criterio colectivo, esto es las experiencias o datos colectivas, y no tanto sobre el individual de cada empresa en particular.

\footnotetext{
${ }^{78}$ STS $\$ Penal 6 de noviembre 2017 (rec. 10006/2017): "no se ha llevado a cabo ninguna pericia que acredite la adecuación a los criterios estadísticos suministrados por el teorema de Bayes o propios del denominado método hipergeométrico. Por lo que mal estaría el Tribunal en condiciones de advertir que el muestreo no garantiza la probabilidad postulada sobre la naturaleza de toda la sustancia intervenida en el alijo". En términos similares, SSTSIPenal 23 de noviembre 2015 (rec. 10386/2015); 1 de marzo 2011 (rec. 1174/2010); 18 de septiembre 2009 (rec. 10031/2009). Por otra parte, la SAPIValladolid 8 de octubre 2019 (rec. 558/2019) afirma: "Y el estado actual de la ciencia permite afirmar, con una certeza casi absoluta (según el teorema de Bayes), que el resto biológico de una persona localizado en un lugar acredita la presencia de esa persona en él, en el sentido que sus manos han estado en contacto con la superficie u objeto en que aparecen, sea este fijo o en un mueble móvil (entre otras, STS de 18-10-2.017), lo cual permite afirmar que se trate de un "indicio significativo" (entre otras, STS de 14-2-2.012) o de " singular potencia acreditativa" (entre otras, STS de 17-1-2.019 ó 12-4-2.018)".

${ }^{79}$ STSJC-A Madrid 20 de junio 2019 (rec. 114/2017).

${ }^{80}$ STSJ La Rioja 27 de febrero 2012 (rec. 18/2012). O, como apunta Sara POSE VIDAL ("El periodo de consultas: la documentación preceptiva a entregar por el empresario", en Godino Reyes, dir., Tratado de Despido colectivo, Valencia, Tirant Lo Blanch, 2016, p. 259), "el informe técnico al que alude el precepto reglamentario tiene un contenido mucho más abierto que el económico, pero en todo caso debe ser absolutamente riguroso en su análisis y fundarse en datos fehacientemente constatados respecto de la evolución de la empresa, del sector y del mercado".

${ }^{81}$ SILVER, Nate, La señal y el ruido, op. cit., pp. 545 y 545.
} 
El teorema de Bayes, además, contribuiría a clarificar el alcance del control judicial en este ámbito. $\mathrm{O}$, al menos, a priori (y siempre que fuera bien aplicado y comprendido), disiparía la sospecha de intromisión ilegítima que, a partir de la reforma de 2012, se proyectó sobre el proceso de intervención judicial. Especialmente porque permite (Ana SÁNCHEZ-RUBIO ${ }^{82}$ ) "incorporar información previa de un suceso además de permitir incorporar información posterior cuando ésta sea accesible". Lo que, en términos de prueba procesal es especialmente relevante, dado que "mide el impacto que, sobre la probabilidad subjetiva previa del hecho que se pretende acreditar [en nuestro ejemplo, la infidelidad de nuestra pareja], provoca la toma en consideración de la prueba estadística [probabilidad de que la prenda aparezca como condición de que se está produciendo un engaño]. Su utilidad procesal, por tanto, consiste en ser un instrumento que permite combinar información estadística sobre un suceso, con información que carece de esa naturaleza, proporcionando una valoración final agregada de la probabilidad del suceso".

Por otra parte ${ }^{83}$, "la aportación del teorema bayesiano permite restablecer el principio de libre valoración de la prueba en toda su extensión cuando parecía que, precisamente, la aplicación de los métodos científicos reducía la capacidad judicial de apreciar críticamente los resultados probatorios". En efecto ${ }^{84}$, "uno de los aspectos positivos de la perspectiva bayesiana es que, por el hecho de reconocer explícitamente que tenemos creencias previas que influyen en nuestra forma de interpretar los nuevos datos, ofrece una descripción muy buena de nuestra forma de reaccionar ante los cambios que se producen en nuestro entorno". De hecho, nada en el teorema "nos impide tener convicciones que consideremos absolutamente ciertas. Si creemos que hay un cien por cien (o un 0 por ciento, lo mismo da) de probabilidades de que Dios exista, según el teorema de Bayes ni todas las pruebas del mundo podrán convencernos de lo contrario".

$\mathrm{Y}$, si bien es cierto ${ }^{85}$ que "realizar predicciones a partir de nuestras creencias es la mejor (y tal vez la única) forma de ponernos a prueba", conviene no confundir (Ana SÁNCHEZ-RUBIO ${ }^{86}$ ) "las probabilidades estadísticas con el valor de la prueba", y conviene ser muy cautelosos a la hora de evitar "formular e interpretar los resultados obtenidos según la opción que más convenga a cada parte, u olvidar que las pruebas

\footnotetext{
${ }^{82}$ SÁNCHEZ-RUBIO, Ana, "Los peligros de la probabilidad y la estadística como herramientas para la valoración jurídico-probatoria", op. cit., pp. 199 y 201.

${ }^{83}$ Siguiendo con SÁNCHEZ-RUBIO, op. cit., pp. 201 y 202 - que cita a VARGAS ÁVILA, Rodrigo, "La valoración de la prueba científica de ADN en el proceso penal", Prolegómenos. Derechos y valores, núm. 25, 2010, p. 143.

${ }^{84}$ SILVER, Nate, La señal y el ruido, op. cit., pp. 312 y 313.

${ }^{85}$ SILVER, Nate, La señal y el ruido, op. cit., pp. 313.

${ }^{86}$ SÁNCHEZ-RUBIO, Ana, "Los peligros de la probabilidad y la estadística como herramientas para la valoración jurídico-probatoria”, op. cit., p. 203.
} 
estadísticas de un caso deben valorarse junto con otras muchas que no ofrecen resultados estadísticos".

Y es obvio que esta aproximación debe llevarse a cabo con la mayor de las cautelas y conocimiento experto posibles. En todo caso y en un ejercicio práctico totalmente "libre", al no disponer de ningún caso real cuyos datos puedan encajar en la matriz bayesiana, permítanme proponerles el siguiente ejemplo ("inspirado" en lo expuesto en la citada STS 25 de febrero 2015, rec. 74/2014, sobre la productora de una televisión autonómica). Así pues, debe partirse de la base de que la hipótesis (que coincide con el supuesto de hecho de la norma y, por ende, que habilita las extinciones contractuales) es que la situación económica de la empresa puede empeorar en el caso (por ejemplo) de pérdida de un cliente ("C1") importante desde el punto de vista de la facturación.

\section{Probabilidad previa}

\begin{tabular}{|l|l|l|}
\hline $\begin{array}{l}\text { Estimación de que la situación económica del } \\
\text { sector al que pertenece la empresa sea negativa } \\
\text { (recuerden que esta estimación se refiere al } \\
\text { momento anterior a la pérdida del cliente) }\end{array}$ & $\mathrm{x}$ & $10 \%$ \\
\hline
\end{tabular}

2. Sucede algo: pérdida de un cliente ("Cl”)

\begin{tabular}{|l|l|l|}
\hline $\begin{array}{l}\text { Probabilidad de que la pérdida de un cliente } \\
\text { "C1" sea la condición para un empeoramiento } \\
\text { de la situación económica de la empresa }\end{array}$ & $\mathrm{y}$ & $65 \%$ \\
\hline $\begin{array}{l}\text { Probabilidad de que la pérdida del cliente "C1" } \\
\text { sea la condición para que no se produzca un } \\
\text { empeoramiento de la situación económica de } \\
\text { la empresa }\end{array}$ & $\mathrm{z}$ & $20 \%$ \\
\hline
\end{tabular}

\section{Probabilidad posterior:}

\begin{tabular}{|l|c|c|}
\hline $\begin{array}{l}\text { Estimación corregida sobre las probabilidades } \\
\text { de que la pérdida del cliente "C1” empeore la } \\
\text { situación económica de la empresa }\end{array}$ & $\frac{x y}{x y+z(1-x)}$ & $26 \%$ \\
\hline
\end{tabular}

\footnotetext{
${ }^{87}$ También podría hacerse esta estimación a partir de la situación de la empresa en concreto.
} 
Aunque estas estimaciones se llevan a cabo a partir de datos ficticios, el resultado obtenido (como en el ejemplo del engaño anterior) es interesante porque desvela información muy clarificadora.

Reparen que la pérdida del cliente "C1", a pesar de una primera intuición negativa sobre su incidencia (dado que la probabilidad era del 65\%) ha quedado "ajustada" al 26\%. El hecho de que esto sea así se debe en parte a que, en este caso, la variable "z" está informando sobre el número de "falso positivos" que se dan en estas situaciones. Es decir, situaciones en las que los indicios detectados no son indicativos de un determinado fenómeno (en este caso, al ser del 20\%, quiere decir que en 1 de cada 5 casos se dan).

No obstante, aunque estos datos no sean tan "alarmantes" como inicialmente podía intuirse (pues, es obvio que el $26 \%$ es significativamente inferior al 65\%) debe tenerse en cuenta que la probabilidad ha subido del 10\% inicial (para el sector) al 25\% (para esta específica empresa en estas circunstancias concretas).

Ahora bien (siguiendo con datos ficticios), para el caso de que, por ejemplo, la empresa pierda un nuevo cliente ("C2"), menos importante en términos de facturación (con un $40 \%$ para la variable "y", y del 10\% para la "z"), los resultados serían los siguientes (en este caso, recuerden que debe tomarse como estimación previa - "x" - la probabilidad obtenida del anterior cálculo: $26 \%$ ):

\section{Probabilidad previa}

\begin{tabular}{|l|l|l|}
\hline $\begin{array}{l}\text { Estimación de que la situación económica del } \\
\text { sector al que pertenece la empresa sea negativa } \\
\text { (recuerden que esta estimación se refiere al } \\
\text { momento anterior a la pérdida del cliente) }\end{array}$ & $\mathrm{x}$ & $26 \%$ \\
\hline
\end{tabular}

\section{Sucede algo: pérdida de un cliente ("C2")}

\begin{tabular}{|l|l|l|}
\hline $\begin{array}{l}\text { Probabilidad de que la pérdida de un cliente } \\
\text { "C2" sea la condición para un empeoramiento } \\
\text { de la situación económica de la empresa }\end{array}$ & $\mathrm{y}$ & $40 \%$ \\
\hline $\begin{array}{l}\text { Probabilidad de que la pérdida del cliente "C2" } \\
\text { sea la condición para que no se produzca un } \\
\text { empeoramiento de la situación económica de } \\
\text { la empresa }\end{array}$ & $\mathrm{z}$ & $10 \%$ \\
\hline
\end{tabular}

\section{Probabilidad posterior:}




\begin{tabular}{|l|c|c|}
\hline $\begin{array}{l}\text { Estimación corregida sobre las probabilidades } \\
\text { de que la pérdida del cliente "C2" empeore la } \\
\text { situación económica de la empresa }\end{array}$ & $\frac{x y}{x y+z(1-x)}$ & $58 \%$ \\
\hline
\end{tabular}

Y, como se ha apuntado, recuerden que estas estimaciones pueden estar sujetas a iteración a medida que se tenga acceso a nuevas evidencias.

En este caso, es claro que la situación se ha agravado, dado que la probabilidad de que la pérdida del segundo cliente ("C2") provoque un efecto negativo en la situación económica de la empresa, se ha más que duplicado (pasando del 26\% al 58\%). De hecho, aunque la probabilidad del hecho en sí (pérdida de "C2") era del $40 \%$, éste ha experimentado un notable efecto amplificador. Por otra parte, en este caso, el número de falsos positivos - "z" - se ha visto notablemente reducida con respecto al escenario inicial, estimándose de 1 de cada 10 casos (lo que parece razonable pensar que así podía suceder).

En estas circunstancias, podría concluirse que la proyección de la empresa está en una previsible espiral negativa. Lo que, probablemente, justificaría el despido preventivo por causas económicas.

\section{Valoración final}

El ser humano, pese a que no puede evitar planificar y hacer proyecciones, tiene una capacidad extremadamente limitada para predecir el futuro. Como se ha tratado de evidenciar, no sólo no podemos fiarnos de nuestro conocimiento pasado, sino que, cuando tratamos de proyectar nuestras experiencias pretéritas a escenarios posibles, podemos incurrir (inconscientemente) en valoraciones muy alejadas de la senda del curso de los acontecimientos. E, incluso, la ingente disponibilidad de datos que la era de la información nos provee y el crecimiento exponencial de hipótesis posibles que la misma habilita, ha ahondado (profundamente) en nuestras limitaciones para comprender el presente. En el fondo ${ }^{88}$, corremos el riesgo grave de confundir la aproximación con la realidad. Lamentablemente, la alarma sanitaria provocada por el COVID-19 nos ha sometido a un (brutal) baño de realidad.

Esta matriz es predicable a los supuestos del despido por causas económicas preventivo (aunque no sólo), especialmente, porque se desarrolla en un contexto (el empresarial) de incertidumbre por antonomasia. De hecho, podría concluirse que la correcta aplicación

${ }^{88}$ SILVER, Nate, La señal y el ruido, op. cit., pp. 544. 
de este subtipo resolutorio exigiría la sujeción a la lógica bayesiana (aunque es obvio que podría exportarse a otros muchos ámbitos resolutorios o no, siempre que estén caracterizados por la incertidumbre).

El análisis bayesiano ${ }^{89}$ se aplica en muchos ámbitos de la ciencia y de la industria y ha sido calificado ${ }^{90}$ como uno de "los mayores descubrimientos de la inteligencia humana". Y, dado su potencial, es utilizado para tomar decisiones sobre la base de informaciones incompletas, forzando la búsqueda de nuevos datos para corregir, o confirmar, tales decisiones. Es un método idóneo para este contexto porque permite "prever razonablemente cierto desarrollo de acontecimientos que se producirá en un futuro y se intenta obtener la máxima información sobre los desarrollos más probables".

Tiene la virtud de que permite" "detectar en qué casos nuestro enfoque instintivo es excesivamente rudimentario". En el fondo, "en la cosmología bayesiana, la predicción es el patrón con el que se mide el progreso. Es posible que nunca logremos conocer la verdad con una certeza al cien por cien, pero realizar predicciones correctas es la única forma de saber si nos estamos acercando al objetivo". Y, además, en la medida que "nos obliga a especificar de forma explícita la probabilidad que otorgamos a algún acontecimiento antes de empezar a sopesar las pruebas disponibles", permite tener en cuenta nuestras creencias previas al respecto y esto permite evaluar la información de que se dispone en su contexto (y de este modo distinguir entre la "señal" y el "ruido").

A la luz de lo anterior, ciertamente, no existe ninguna razón para que el ámbito del derecho y, en particular, el laboral quede excluido.

En todo caso, a pesar de la simplicidad formal del teorema de Bayes (en la formulación expuesta, no es más que una multiplicación y una división), lo difícil es poner los ingredientes exactos ${ }^{92}$. Y, en este sentido, es obvio que requiere una cautelosa aproximación, aplicación y evaluación (como ya se está haciendo en muchos ámbitos).

Respetando estas claves, creo que podría erigirse en un poderoso instrumento para dar seguridad jurídica al proceso de constatación y control de las causas económicas resolutorias, complementando los existentes.

\footnotetext{
${ }^{89}$ MLODINOW, Leonard, El andar del borracho, Barcelona, Crítica, 2019, p. 126.

${ }^{90}$ PIATTELLI PALMARINI, Massimo, Los túneles de la mente, op. cit., p. 108.

${ }^{91}$ SILVER, Nate, La señal y el ruido, op. cit., pp. 299, 309 y 545.

${ }^{92}$ PIATTELLI PALMARINI, Massimo, Los túneles de la mente, op. cit., 111.
} 


\section{Bibliografía}

DAMASIO, Antonio R. El error de Descartes, Santiago de Chile, Editorial Andrés Bello, 1996.

DEUTSCH, David, La estructura de la realidad, Barcelona, Anagrama, 1999.

FALGUERA i BARÓ, Miquel, "La causalidad de los despidos económicos, técnicos, organizativos y productivos después de la ley 3/2012: reflexiones tras un año de doctrina judicial por la vía del artículo 124 LRJS”, Revista Jurisdicción Social, núm. 133, 2013 (versión digital).

FELDMAN BARRET, Lisa, La vida secreta del cerebro, Barcelona, Paidós, 2018.

GAZZANIGA, Michael S., El instinto de la conciencia, Barcelona, Paidós, 2019.

GIGERENZER, Gerd, Decisiones instintivas, Barcelona, Ariel, 2018.

GILBERT, Daniel, Tropezar con la felicidad, Barcelona, Ariel, 2017.

HARARI, Yuval N., Homo deus, Barcelona, Penguin Random House, 2016.

KAHNEMAN, Daniel, Pensar rápido, pensar despacio, Barcelona, Debolsillo, 2012.

MLODINOW, Leonard, El andar del borracho, Barcelona, Crítica, 2019.

MOLINS GARCÍA-ATANCE, Juan, "Las causas económicas, técnicas, organizativas y de producción del despido objetivo y colectivo", Aranzadi Social, núm. 11, 2011 (versión digital).

MONEREO PÉREZ, José Luís, El despido colectivo y sus elementos configuradores tras las recientes reformas, Valencia, Tirant Lo Blanch, 2012.

MONEREO PÉREZ José Luís y GUINDO MORALES, Sara, "El despido colectivo fundado en causas económicas”, Derecho de las relaciones laborales, núm. 9, 2018 (versión digital).

OSTBY, Hilde y OSTBY, Ylva, El libro de la memoria, Barcelona, Ariel, 2019.

OVEJERO BERNAL, Anastasio, Psicología social, Madrid, Biblioteca Nueva, 2015. 
PIATTELLI PALMARINI, Massimo, Los túneles de la mente, Barcelona, Crítica, 1995.

POSE VIDAL, Sara, "El periodo de consultas: la documentación preceptiva a entregar por el empresario", en Godino Reyes (dir.), Tratado de Despido colectivo, Valencia, Tirant Lo Blanch, 2016.

VARGAS ÁVILA, Rodrigo, "La valoración de la prueba científica de ADN en el proceso penal”, Prolegómenos. Derechos y valores, núm. 25, pp. 127-146, 2010.

SÁEZ LARA, Carmen, Reestructuraciones Empresariales y Despidos Colectivos, Valencia, Tirant Lo Blanch, 2015.

SÁNCHEZ-RUBIO, Ana, "Los peligros de la probabilidad y la estadística como herramientas para la valoración jurídico-probatoria", Revista Brasileira de Direito Processual Penal, Vol. 4, núm. 1, pp. 183-214, 2018.

SCHULZ, Kathryn, En defensa del error, Madrid, Siruela, 2015.

SILVER, Nate, La señal y el ruido, Barcelona, Atalaya, 2014.

SOLER FERRER, Felipe, "La nueva regulación del despido por causas objetivas", Diario La Ley, núm. 7548, 2011 (versión digital).

SUNSTEIN, Cass R., Leyes de miedo, Buenos Aires, Katz, 2009.

SUNSTEIN, Cass R., Riesgo y razón, Buenos Aires, Katz, 2006.

SUTHERLAND, Stuart, Irracionalidad: el enemigo interior, Madrid, Alianza, 1996.

TALEB, Nassim N., Jugarse la piel, Barcelona, Paidós, 2019.

TALEB, Nassim N., El cisne negro, Barcelona, Paidós, 2011.

THALER, Richard H., Todo lo que he aprendido con la psicología económica, Barcelona, Deusto, 2016.

TIROLE, Jean, La economía del bien común, Barcelona, Debolsillo, 2018.

TOMASELLO, Michael, Los orígenes culturales de la cognición humana, Buenos Aires, Amorrurtu Editores, 2007. 